\title{
Dentistry and Medical Complexities
}

\author{
Salah Sakka ${ }^{\mathrm{a}, \mathrm{d}}$, Saleh Nasir Azzeghaiby ${ }^{\mathrm{b}}$, Amr Alyasein ${ }^{\mathrm{c}}$, \\ Salah Hanouneh ${ }^{c}$
}

\begin{abstract}
Dentistry is a safe profession, even for most medically complex patients. In several cases, fear treating such patients may be based not on scientific specifics but rather on a "mythology" of the dangers of dentistry. The complexities of anticoagulation, artificial joint infections, local anesthetics with or without vasoconstrictors, and endocarditis are discussed. Neither continuous anticoagulation nor antiplatelet medications should be withdrawn for dental surgery. Most artificial joint patients should not receive antibiotic prophylaxis. Local anesthetics and vasoconstrictors can be used safely in most medically complex patients. Although dental treatment is not usually a risk factor for endocarditis, practitioners should consult the updated 2008 American Heart Association statement for recommendations for endocarditis prevention.
\end{abstract}

Keywords: Dentistry; Compromised patient; Medical complexities

\section{Introduction}

Many dental surgeons, from those just out of university to expert practitioners, approach dental treatment of medically complex patients with a mixture of two feelings: fear and paranoia. Many dental surgeons may recommend certain type of treatment in patients, because that was the way they were taught. Tradition is not necessarily a good way to practice dentistry. Physician consultation, rather than insulating the dental surgeon from liability in malpractice suits, can actually be a contributing factor in a malpractice suit, particularly if the dentist relied on medical advice that the dentist knew

Manuscript accepted for publication May 14, 2015

aDepartment of Oral and Maxillofacial Surgery, Al-farabi Colleges, Riyadh, KSA

${ }^{b}$ Board of Trustees, Al-farabi Colleges, Riyadh, KSA

${ }^{\mathrm{c}} \mathrm{Al}$-farabi Colleges, Riyadh, KSA

dCorresponding Author: Salah Sakka, Al-farabi Dental College, P.O. Box

85184, Riyadh 11691, KSA. Email: salah.sakka@hotmail.com

doi: http://dx.doi.org/10.14740/jcs187e or reasonably should have known to be mistaken [1]. Medical consultation can and should be an important adjunct to dental surgery decisions. However, it is not an alternate for good clinical judgment based on up to date scientific medical and dental studies and recommendations. As a general rule, if there is sufficient piece of information from the patient's medical history, then well-known scientific medical and dental recommendations are adequate to treat the patient. If there is information unknown to both the patient and the dentist, it may be suitable to consult the physician for such medical information.

\section{Patients on Anticoagulant Drugs}

Although these medications are often life-saving, they can also raise the risk of bleeding after dental surgery. Anticoagulation is measured by the international normalized ratio (INR) or prothrombin time ratio (PTR). The American Heart Association (AHA) [2] and the American College of Chest Physicians [3] recommend a therapeutic level of anticoagulation of no higher than INR 3.5 or about PTR 2.0 (although other centers [4] have declared no higher than INR 4.0 or about PTR 2.2). A survey in 1996 revealed that $73 \%$ of physicians recommended withdrawing warfarin before some or all dental surgeries. Other physicians recommended withdrawing warfarin for root canal therapy than for professional cleanings, although root canal therapy brings little or no danger of bleeding [5].

Continuous aspirin as antiplatelet medication is often taken to avoid a heart attack. Many physicians recommend withdrawing aspirin before dental surgery [6]. Although there have been case reports of postoperative bleeding after surgical dental treatments $[7,8]$, controlled and clinical studies suggest that there is no indication to discontinue aspirin for persons requiring tooth extraction $[9,10]$.

Anticoagulants and antiplatelet drugs are often life-saving; dental surgery is almost never life-threatening. When used at currently recommended therapeutic levels, these drugs should not be withdrawn for surgical dental treatments. For patients on continuous antiplatelet medications such as aspirin, physician consultation is usually not necessary unless there are areas of concern in the medical history, particularly those that affect bleeding time [11]. 
Table 1. Medical Complexities and Related Guidance Before Commencing Dental Surgery

\begin{tabular}{ll}
\hline Medical complexity & Guidance before dental treatment \\
\hline Patients on anticoagulants & $\begin{array}{l}\text { Continue medications unless patients receive higher } \\
\text { than recommended level of anticoagulation }\end{array}$ \\
$\begin{array}{l}\text { Artificial joint infections } \\
\text { Medically compromised } \\
\text { patients and vasoconstrictors }\end{array}$ & $\begin{array}{l}\text { Antibiotic prophylaxis not indicated } \\
\text { for patients with cardiovascular disease }\end{array}$ \\
Infective endocarditis & Consult the 1997 AHA and its 2008 update \\
\hline
\end{tabular}

\section{Dental Surgery, Antibiotics and Artificial Joint Infections}

The number of joint replacement surgeries is increasing as the population ages. These artificial joints can become contaminated from bacteremias; and such infections can be very severe, leading to further surgical interventions, defects and even death. However, it is understandable that it is not routinely indicated for most dental patients with total joint replacements [12].

The only patients for whom antibiotic prophylaxis should even be considered is a small number of high risk artificial joint patients (e.g., patients with previous artificial joint infections, insulin-dependent diabetes and radiation-induced immune-suppression) [13].

Following their standard protocols for periodic review of existing advisory statements, the American Dental Association (ADA) and American Academy of Orthopedic Surgeons (AAOS) and their expert consultants recently reviewed the 1997 statement [13]. The 2003 statement includes some modifications of the classification of patients at potential risk and of the incidence stratification of bacteremic dental procedures, but no changes in terms of suggested antibiotics and antibiotic regimens [12]. The statement concludes that antibiotic prophylaxis is not indicated for dental patients with pins, plates or screws, nor is it routinely indicated for most dental patients with total joint replacements.

It may be wise to consult the patient's physician if there is a contradiction between what the physician recommends and what the AAOS/ADA 2003 statement recommends ruling out, if the physician has information about the patient's medical history that is unknown to the dentist.

\section{Medically Compromised Patients and Vasocon- strictors Added to Local Anesthetics}

The safety of local anesthetics with vasoconstrictors has often been questioned. However, they might be used in most cases of both medically-compromised and healthy patients [14]. In fact, the use of epinephrine can be justified for most dental procedures, but it may be necessary to minimize the dose for patients receiving specific medications and those with cardiovascular disease [15].

Contrary to the information in certain drug monographs, epinephrine can be given to patients receiving monoamine oxi- dase inhibitors [16] as clinical studies in human and animals have shown that cardiovascular interactions between MAOI and dental vasoconstrictors are not produced $[17,18]$.

\section{Dental Surgery, Antibiotics and Infective Endo- carditis}

Endocarditis is a rare heart infection which is caused by bacteremia that refers to the bacterial invasion of the bloodstream. Generally, such bacteria quickly and harmlessly pass through the system. However, in rare cases, the bacteria can colonize on the heart valve, causing a heart infection known as infective endocarditis [19]. Several studies have shown that dental procedures cause very few incidents of endocarditis of oral origin [20], and most cases of which are caused by frequent bacteremias from poor dental hygiene (bleeding gums and longstanding dental infections) [21]. In general, it is possible that a dental procedure can cause a bacteremia that leads to endocarditis, and patients with pre-existing heart valve abnormalities are at greater risk of developing endocarditis than those without such abnormalities [22].

The AHA has issued statements on the prevention of endocarditis, most recently in 2008 [23]. The most important preventive measures for endocarditis are good oral health and home care, and the AHA also recommends that some patients with certain heart problems should receive antibiotic prophylaxis before certain dental procedures that cause significant bleeding. The 2008 AHA statement, written by a prominent group of experts in endocarditis, is a simple and important guide for the practicing dentist. It provides a list of patients and dental procedures for which antibiotic prophylaxis is recommended and those for which it is not recommended (Table 1). The updated recommendations include the following: 1) only an extremely small number of cases of infective endocarditis might be prevented by antibiotic prophylaxis for dental procedures even if such prophylactic therapy were $100 \%$ effective; 2) IE prophylaxis for dental procedures should be recommended only for patients with underlying cardiac conditions associated with the highest risk of adverse outcome from IE; 3) for patients with these underlying cardiac conditions, prophylaxis is recommended for all dental procedures that involve manipulation of gingival tissue or the periapical region of teeth or perforation of the oral mucosa; 4) prophylaxis is not recommended based solely on an increased lifetime risk of acquisition of IE. 


\section{Conclusions}

Dental patients with medically complex situations may not be so difficult. Neither continuous anticoagulation nor continuous antiplatelet medications should be stopped for surgical dental treatments, unless patients are at higher than therapeutic level of anticoagulation or they have additional medical concerns. Most patients with artificial joints should not require antibiotic prophylaxis, and patients at high risk are the ones for whom antibiotic prophylaxis should be considered. The use of vasoconstrictors can be justified for most dental treatments, and physician consultation is only indicated when more information is needed about the patient's complex medical history. Dentists should consult the 1997 AHA statement and its 2008 update for recommendations on antibiotic prophylaxis in patients at danger of endocarditis. At this point, such consultation can be an important adjunct to the dental surgery. However, it should not be a substitute for the dental surgeon's own clinical decision evidenced by recent scientific literature and available international medical and dental guidelines.

\section{References}

1. Wahl MJ. Prosthetic joint patients. J Am Dent Assoc. 1994;125(6):664, 666.

2. Hirsh J, Fuster V. Guide to anticoagulant therapy. Part 2: Oral anticoagulants. American Heart Association. Circulation. 1994;89(3):1469-1480.

3. Hirsh J, Dalen JE, Deykin D, Poller L. Oral anticoagulants. Mechanism of action, clinical effectiveness, and optimal therapeutic range. Chest. 1992;102(4 Suppl):312S$326 \mathrm{~S}$.

4. Cannegieter SC, Rosendaal FR, Wintzen AR, van der Meer FJ, Vandenbroucke JP, Briet E. Optimal oral anticoagulant therapy in patients with mechanical heart valves. N Engl J Med. 1995;333(1):11-17.

5. Wahl MJ, Howell J. Altering anticoagulation therapy: a survey of physicians. J Am Dent Assoc. 1996;127(5):625626, 629-630, 633-624 passim.

6. Thomason JM, Seymour RA, Murphy P, Brigham KM, Jones P. Aspirin-induced post-gingivectomy haemorrhage: a timely reminder. J Clin Periodontol. 1997;24(2):136-138.

7. Foulke CN. Gingival hemorrhage related to aspirin ingestion. A case report. J Periodontol. 1976;47(6):355-357.

8. McGaul T. Postoperative bleeding caused by aspirin. J Dent. 1978;6(3):207-209.

9. Brennan MT, Valerin MA, Noll JL, Napenas JJ, Kent ML, Fox PC, Sasser HC, et al. Aspirin use and post- operative bleeding from dental extractions. J Dent Res. 2008;87(8):740-744.

10. Thomas S, Katbab H, abu Fanas SH. Do preoperative cutaneous bleeding time tests predict the outcome of intraoral surgical bleeding? Int Dent J. 2010;60(4):305-310.

11. Ardekian L, Gaspar R, Peled M, Brener B, Laufer D. Does low-dose aspirin therapy complicate oral surgical procedures? J Am Dent Assoc. 2000;131(3):331-335.

12. Antibiotic prophylaxis for dental patients with total joint replacements. J Am Dent Assoc. 2003;134(7):895-899.

13. Advisory statement. Antibiotic prophylaxis for dental patients with total joint replacements. American Dental Association; American Academy of Orthopaedic Surgeons. J Am Dent Assoc. 1997;128(7):1004-1008.

14. Wahl MJ, Brown RS. Dentistry's wonder drugs: local anesthetics and vasoconstrictors. Gen Dent. 2010;58(2):114123; quiz 124-115.

15. Haas DA. An update on local anesthetics in dentistry. J Can Dent Assoc. 2002;68(9):546-551.

16. Gomez-Moreno G, Guardia J, Cutando A, Calvo-Guirado JL. Pharmacological interactions of vasoconstrictors. Med Oral Patol Oral Cir Bucal. 2009;14(1):E20-27.

17. Yagiela JA. Adverse drug interactions in dental practice: interactions associated with vasoconstrictors. Part V of a series. J Am Dent Assoc. 1999;130(5):701-709.

18. Naftalin LW, Yagiela JA. Vasoconstrictors: indications and precautions. Dent Clin North Am. 2002;46(4):733746, ix.

19. Pallasch TJ. A critical appraisal of antibiotic prophylaxis. Int Dent J. 1989;39(3):183-196.

20. Strom BL, Abrutyn E, Berlin JA, Kinman JL, Feldman RS, Stolley PD, Levison ME, et al. Dental and cardiac risk factors for infective endocarditis. A population-based, case-control study. Ann Intern Med. 1998;129(10):761769.

21. Guntheroth WG. How important are dental procedures as a cause of infective endocarditis? Am J Cardiol. 1984;54(7):797-801.

22. Steckelberg JM, Wilson WR. Risk factors for infective endocarditis. Infect Dis Clin North Am. 1993;7(1):9-19.

23. Wilson W, Taubert KA, Gewitz M, Lockhart PB, Baddour LM, Levison M, Bolger A, et al. Prevention of infective endocarditis: guidelines from the American Heart Association: a guideline from the American Heart Association Rheumatic Fever, Endocarditis and Kawasaki Disease Committee, Council on Cardiovascular Disease in the Young, and the Council on Clinical Cardiology, Council on Cardiovascular Surgery and Anesthesia, and the Quality of Care and Outcomes Research Interdisciplinary Working Group. J Am Dent Assoc. 2008;139(Suppl):3S-24S. 